\title{
Exploring public awareness of the current and future malaria risk zones in South Africa under climate change: a pilot study
}

\author{
Jennifer M Fitchett ${ }^{1}$ (D) Deryn-Anne Swatton ${ }^{1}$
}

Received: 22 April 2020 / Revised: 20 October 2020 / Accepted: 29 October 2020 / Published online: 11 November 2020

(C) ISB 2020

\begin{abstract}
Although only a small proportion of the landmass of South Africa is classified as high risk for malaria, the country experiences on-going challenges relating to malaria outbreaks. Climate change poses a growing threat to this already dire situation. While considerable effort has been placed in public health campaigns in the highest-risk regions, and national malaria maps are updated to account for changing climate, malaria cases have increased. This pilot study considers the sub-population of South Africans who reside outside of the malaria area, yet have the means to travel into this high-risk region for vacation. Through the lens of the governmental "ABC of malaria prevention", we explore this sub-population's awareness of the current boundaries to the malaria area, perceptions of the future boundary under climate change, and their risk-taking behaviours relating to malaria transmission. Findings reveal that although respondents self-report a high level of awareness regarding malaria, and their boundary maps reveal the broad pattern of risk distribution, their specifics on details are lacking. This includes over-estimating both the current and future boundaries, beyond the realms of climate-topographic possibility. Despite over-estimating the region of malaria risk, the respondents reveal an alarming lack of caution when travelling to malaria areas. Despite being indicated for high-risk malaria areas, the majority of respondents did not use chemoprophylaxis, and many relied on far less-effective measures. This may in part be due to respondents relying on information from friends and family, rather than medical or governmental advice.
\end{abstract}

Keywords Vector-borne disease $\cdot$ Malaria $\cdot$ Mapping $\cdot$ Risk aversion $\cdot$ Climate change

\section{Introduction}

Malaria is a dangerous and potentially fatal vector-borne disease caused by the Plasmodium parasite, transmitted to humans through the bite of an infected female Anopheles mosquito (Cohuet et al. 2010; Cella et al. 2019). In 2018, an estimated 228 million cases of malaria were reported globally, similar to 231 million cases for 2017, with a death toll of 435,000 in 2017 and 405,000 in 2018 (Alonso and Noor 2017; WHO 2019a,b). The burden of malaria was disproportionately borne by developing nations, particularly in the African continent, which accounted for $92 \%$ and $93 \%$ of the malaria cases and deaths recorded in 2018, respectively

Jennifer M Fitchett

Jennifer.Fitchett@wits.ac.za

1 School of Geography, Archaeology and Environmental Studies, University of the Witwatersrand, Johannesburg, South Africa
(Alonso and Noor 2017; WHO 2019b). In 2016, in an effort to combat malaria, the World Health Organization launched the E-2020 initiative in which it identified 21 countries with the potential to eliminate malaria within their borders by the year 2020 (WHO 2018). South Africa was one of those countries, with an additional local objective of elimination by 2018 (Baker 2018). However, in 2017, South Africa experienced a severe setback in achieving both objectives, reporting 7897 imported and 19,706 indigenous cases of malaria - the highest number of cases reported by any of the 21 identified countries, and more than four times the number of indigenous cases reported in the country in 2016 (WHO 2018; Maharaj et al. 2019; Abiodun et al. 2020). This increase in numbers was due to a range of factors, including an increase in rainfall, temperature, and humidity following an abnormally mild winter (Baker 2018). As a result, the World Health Organization has classed South Africa as "off-track" and has made a number of recommendations as to how the country can steer itself back on course (WHO 2018). Among these are efforts to refine malaria risk maps, to improve public awareness, and 
to revisit malaria strategies (WHO 2018). Due to the unlikelihood of achieving malaria elimination within South Africa by 2020, the South African government has now adopted the self-mandated goal of zero malaria transmission by 2023 , which it announced in the Malaria Elimination Strategic Plan for South Africa 2019-2023 (National Department of Health 2019). One of the primary objectives of the Malaria Elimination Strategic Plan is to "ensure that $90 \%$ of the population affected by malaria receives information and education communication messaging by 2023" (National Department of Health 2019: 25). This objective speaks directly to the recommendations given by the World Health Organization (WHO 2018). The National Guidelines for the Prevention of Malaria in South Africa comprise five key components which are summarized as the "ABC" of malaria prevention, namely Awareness and Assessment of malaria risk, avoidance of mosquito Bites, Compliance with Chemoprophylaxis when indicated, early Detection of malaria disease, and Effective treatment (NDOH 2018a; Baker 2018; Schmidt 2019a, b).

Adding fuel to the fire, climate change is resulting in both an increase in the extent of the South African malaria risk area and the incidence of malaria transmission due to increases in temperature and changes in rainfall patterns (Morris et al., 2013; Abiodun et al., 2020). The spatial distribution of malaria globally is strongly determined by climate (Caminade et al. 2014; Cella et al. 2019). By 2050, a 50\% increase in the probability of malaria incidence is projected globally due to increases in temperature and changes in rainfall patterns (Cella et al. 2019). Temperature has been found to affect both the extent of malaria areas and malaria transmission incidence across the African continent (Eikenberry and Gumel 2019). For South Africa, both temperature and rainfall have been found to affect the malaria rate, with a notable increase in cases following flood events induced by strong tropical storms (Adeola et al. 2019; Makinde and Abiodun 2019). A change in malaria area extent is documented in the frequent updating of the National Department of Health malaria risk maps for South Africa (Coetzee et al. 2013; Morris et al. 2013). Mathematical models have been developed to explore the role of climate in malaria incidence and to aid in projecting future changes in malaria risk distribution, and the risk of transmission (Cella et al. 2019; Eikenberry and Gumel 2019). At a local scale, seasonal malaria forecast models are being developed for South Africa (Kim et al. 2019; Landman et al. 2020). The modelling of the climate impact on malaria distribution and incidence and projections for future incidence are valuable in developing public health policies, and in communication to the public. However, the increased incidence of malaria cases in South Africa in recent years would suggest that effectiveness of the distribution of these maps, particularly with regular updates, remains limited.

A range of studies relating to disparate diseases have revealed the importance of public awareness and understanding of disease risk in determining the precautionary measures that they will adopt (cf. Erhardt and Hobbs 2002; Glik et al. 2004; Goldman et al. 2006; Young et al. 2008 Seale et al. 2010). The role of sources of information, and the level of frequency of communication regarding diseases, is key in the veracity of public awareness (Young et al. 2008). This has been widely understood in South African malaria control efforts (Blumberg et al. 2014), with malaria risk maps for the public dating back to 1938 (Coetzee et al. 2013). However, the efforts in assessing communities' awareness and understanding of malaria risk have largely been limited to regions within the high-risk zone, due to resource scarcity (Maartens et al. 2007; Cox et al. 2018).

In line with the WHO (2018) recommendations, this pilot study seeks to expand on previous work to explore public understanding of the location of the contemporary high-risk malaria zone, the anticipated future expansion of the high-risk malaria zone under climate change, and public behaviour regarding malaria precaution and prophylaxis, among those who reside outside of the malaria risk area, but travel into the high-risk zone on vacation. The aim of this study is to develop a methodology to explore any disconnects between reported and demonstrated awareness and behaviour regarding malaria for gaps in understanding to be addressed more effectively through government intervention, and for targeted awareness campaigns to be developed.

\section{Methods}

Malaria can be found in each of South Africa's neighbouring countries, barring Lesotho, where the altitude and consequent colder temperatures make it inhospitable to the malariacarrying Anopheles mosquito (Blumberg et al. 2014). Within South Africa itself, malaria is confined to the north-eastern reaches of the country, where it is endemic to three of South Africa's nine provinces, namely Limpopo, Mpumalanga, and northern KwaZulu-Natal (Maharaj et al. 2019; Adeola et al. 2019; Fig. 1). According to the latest malaria risk map produced by the South African National Department of Health in December 2018, areas of moderate risk (where chemoprophylaxis is indicated for all travellers from September to May) are concentrated along the border between South Africa and Mozambique and Zimbabwe (Fig. 1). These areas of moderate risk can be found in the Mpumalanga municipality district of Ehlanzeni and in Limpopo in the Mopani and Vhembe municipality districts (Fig. 1). Areas of low risk (where malaria is still present, but only non-drug preventative measures are indicated), however, extend as far west as Limpopo's Waterberg district and as far south as the Umkhanyakude district in KwaZulu-Natal Province (Fig. 1). At present, the regions of highest malaria risk in South Africa have relatively low population density, with no major cities and a large proportion of 


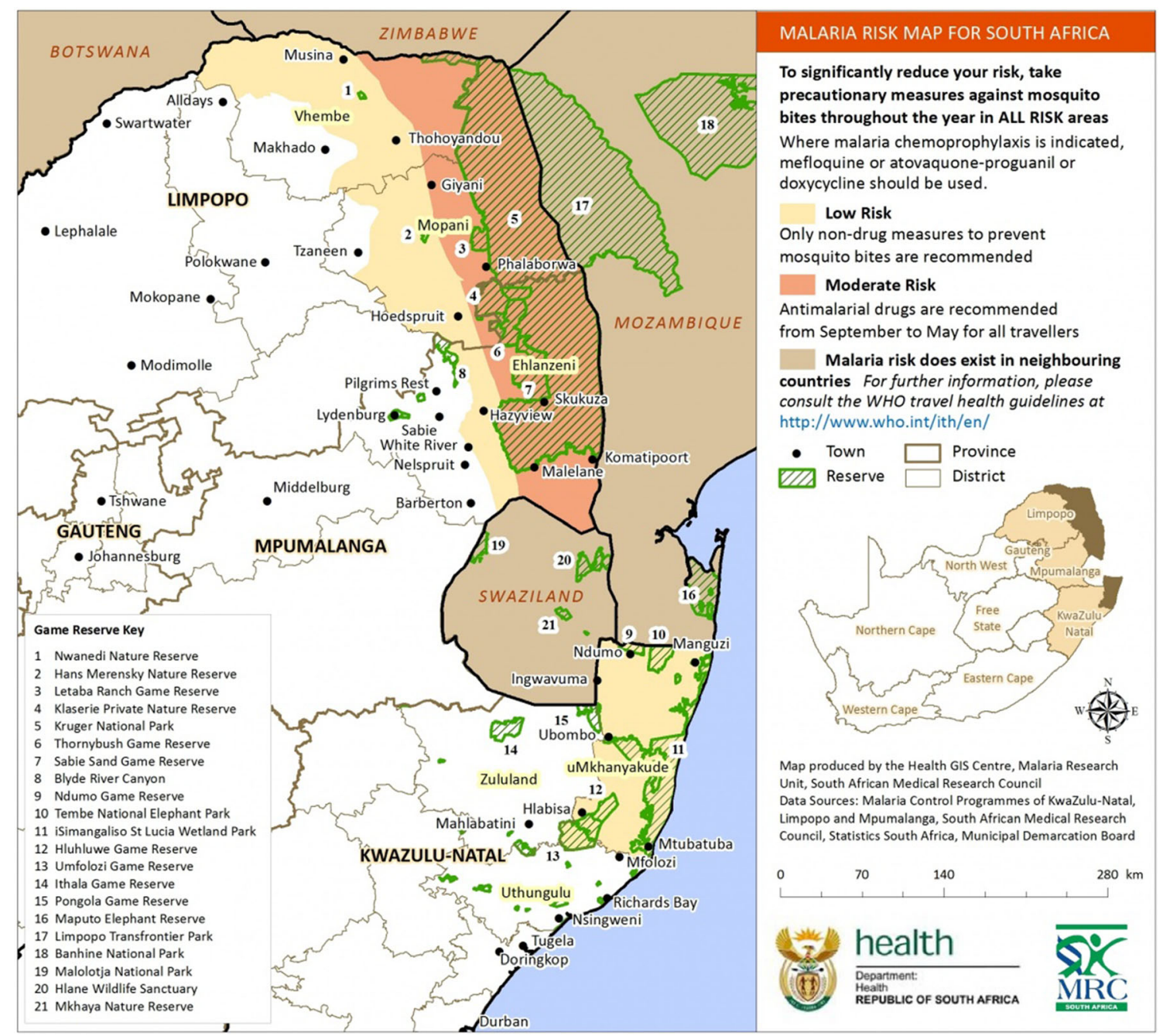

Fig. 1 South African malaria risk map produced by the National Department of Health in December 2018 (After NDoH 2018b)

the high-risk area limited to the Kruger National Park. This does however pose a threat to both local and international tourists visiting the Kruger National Park and nearby game farms and nature reserves, who may be unaware of the risk levels within South Africa.

This research explores respondents' malaria awareness and self-reported behaviours. Therefore, questionnaires were selected as the most appropriate instrument for data collection. Types of questions ranged from multiple choice and Likert scale questions to more open-ended, paragraphstyle questions (Bird, 2009). Topics included respondents' demographics and travel histories, awareness and perception of malaria distribution and risk in Southern Africa, understanding of climate change, and attitudes towards malaria prophylaxis-both in terms of bite prevention and chemoprophylaxis. The closing question of the questionnaire required respondents to draw two lines, in different colours, on a map of Southern Africa: a blue line indicating where they understand the boundary of the present malaria risk zone to be located and a red line indicating where they think the boundary of the malaria risk zone will be located in 20 years' time. The map was created using ArcMap and displayed national and provincial borders, but contained no other information to avoid leading respondents. Questionnaires were distributed in hard copy.

Respondents were identified through a combination of purposive and snowball sampling (Bernard 2013). To ensure a degree of standardization throughout the study sample for this initial pilot study, a target population was identified and a number of parameters were defined. In order to qualify for the study, respondents had to live within the Gauteng Province of South Africa (currently not a malaria area), have at least an undergraduate university degree, and have travelled to a malaria risk area within southern Africa within the last 5 years for leisure purposes. This ensured that the data gathered were relevant and that all respondents were middle- to upper-class leisure tourists with financial means to access to a wide range of precautionary measures to avoid contracting malaria when travelling to malaria areas, and have a reasonable level of education and understanding of health risks. This 
sample is not intended to be representative of the population of South Africa nor the Gauteng Province. Rather, this subgroup is used to determine whether any issues in awareness, behaviour, or use of chemoprophylaxis may warrant further, more extensive investigation. Ethics clearance was obtained from the University of the Witwatersrand's Human Research Ethics Committee (non-medical) prior to entering the field (ethics clearance: gaes-2019-06-01). Given the target population and the minimum requirement of a completed undergraduate degree, no individuals under the age of 18 were approached. Finally, it is important to note that this research dealt exclusively with the data collected from the completed questionnaires and no medical records were accessed or used in this study.

Responses to closed-ended questions from the questionnaire were analyzed using descriptive statistics, while responses to open-ended questions underwent thematic coding and content analysis (Bernard 2013). The hand-drawn maps generated in the last question of the questionnaire were digitized and layered over one another to create composite maps showing areas of consensus/disagreement among respondents. This particular methodology was adapted from a study conducted by Roffe et al. (2019) which mapped agreement among experts regarding rainfall seasonality in South Africa. Finally, the composite maps were compared to the official malaria risk map created by the South African National Department of Health in 2018 to assess their accuracy.

\section{Results}

A total of 38 questionnaires were completed. Of these, six questionnaires were excluded from analysis as the respondents did not fall within the defined parameters of the target population, in most instances as a result of not having visited a malaria area within the past 5 years. Four maps were deemed unusable as the lines drawn could not be digitized as a contiguous vector line and/or what was drawn could not be meaningfully interpreted. Neither the excluded questionnaires nor the unusable maps were used in the creation of the composite maps. In the cases where maps were unusable, but respondents met the selection criteria, the questionnaire responses were captured and included in descriptive statistics and content analysis.

While the intention was to obtain a relatively even distribution of respondents across age groups, due to difficulty accessing people within the older age brackets who met the selection criteria (specifically the criterion relating to tertiary education), a skewed age distribution resulted. Of the 32 respondents who submitted admissible questionnaires, the highest number $(n=14)$ fell into the 20-29 age group. The remaining age groups were comparatively poorly represented, with the 30-39 and 40-49 age categories comprising five respondents each, and the older age groups (50-59 and 60+) each representing one-eighth $(n=4)$ of the sample group. The majority $(n=17)$ of respondents held only a Bachelor's degree, while nine held Honours degrees (a postgraduate qualification in South Africa), one held a Master's degree, and two held a PhD. The remaining three respondents selected "Other" qualifications, in two cases citing university qualifications in the medical or nursing field. This last group, however, cannot be read independently, as respondents with medical or similar degrees may equally have chosen the equivalent qualification to their degree-type from the list provided. The overall spread of tertiary qualifications indicates a well-educated subset of the population. It is worth noting that the various levels of education were spread across the age groups, and it was not simply a case of the older the respondent, the higher their qualification. For example, all respondents in the 40 to 49year-old age group $(n=5)$ reported only holding a Bachelor's degree, whereas of the two respondents in possession of a $\mathrm{PhD}$, one fell into the 30-39 age group and the other into the 60+ age group. This distribution is important, as it means that age and highest qualification are not collinear, but are rather independent factors each of which could be possible determinants of perception, risk assessment, and behaviour. We reiterate that the results of this small group cannot be read as representative of any sub-population, but rather the variety of results indicates a heterogeneity which reveals the importance of further, extensive, investigation.

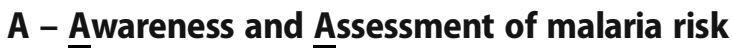

The questionnaire included a mapping exercise in which respondents were required to draw a line across a map of Southern Africa indicating where they understood the boundary of the present malaria risk zone to be located. In this question, respondents were instructed to include the entirety of the Southern African region in the drawing of their malaria zone boundaries. However, eight of the 28 respondents who created usable maps only drew lines across South Africa. Therefore, for the sake of consistency, only the portion of the drawn risk areas which fell within the borders of South Africa was digitized.

Overall, the composite map created from all 28 usable maps reveals a fairly high degree of awareness among respondents regarding the general location of malaria risk areas in South Africa (Fig. 2). Darker blue areas, which show a higher degree of consensus among respondents, can be found in the north-east of the country, concentrated along the border between South Africa and Mozambique and Zimbabwe (Fig. 2). The majority of respondents have also included ESwatini, northern KwaZulu-Natal, and more westerly parts of Limpopo and Mpumalanga in their assessment of malaria risk areas (Fig. 2). This is consistent with the official South African malaria risk map produced by the National Department of Health in 2018 (Fig. 1). However, the composite map also 
Fig. 2 Overlayed digitized maps of respondent's malaria boundary drawing indicating the degree of consensus among respondents regarding the location of malaria risk areas in South Africa $(n=28)$

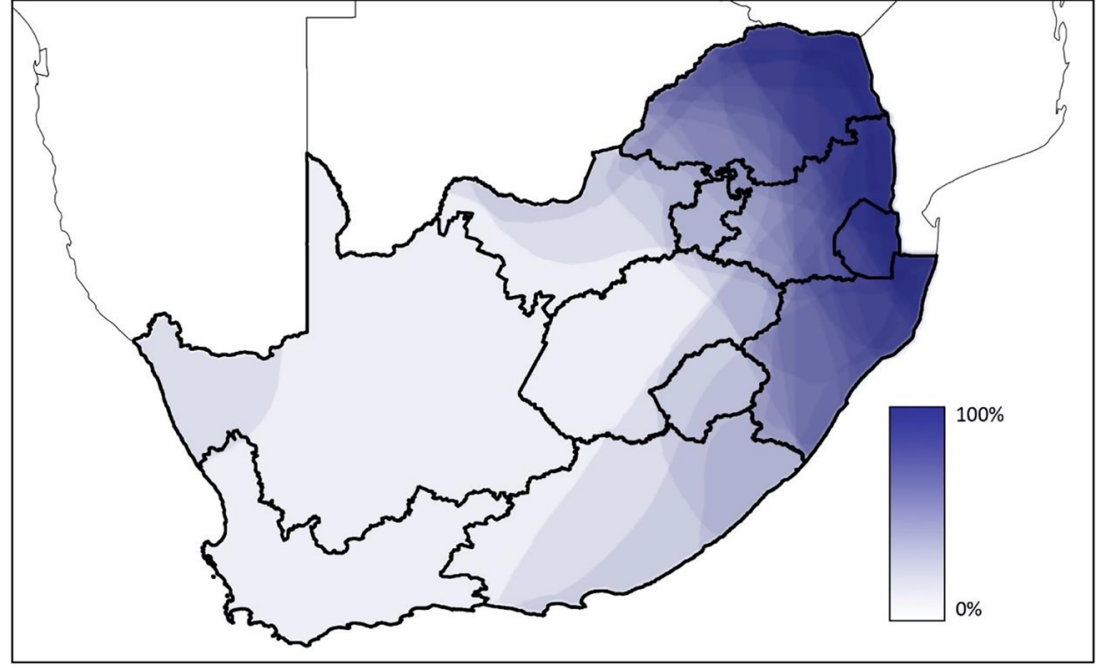

shows that many respondents believe that the malaria risk zone extends further west and south than is indicated on the governmental malaria risk map, with one respondent including the entirety of South Africa in their rendering of the malaria risk zone. Another respondent included the west coast of the Northern Cape, and many drew lines which either dissected or encompassed Lesotho. This indicates a poor awareness of the government-communicated malaria risk maps of South Africa, and moreover a limited understanding of the relationship between climate and malaria distribution, or at least limited awareness of the climate in these areas.

In addition to instructing respondents to map their understanding of malaria risk areas in Southern Africa, the study also sought to assess the accuracy of respondents' selfreported awareness. Respondents were asked whether, prior to taking the questionnaire, they were aware of malaria risk areas in the region. Of the 32 respondents, the vast majority $(n=25)$ indicated that they were aware, while one respondent answered that they were not, and one did not respond. The remaining five respondents stated that they had limited awareness. With such a high degree of self-reported awareness, one would expect more accurate maps than were captured (Fig. 2). Respondents were aware of the general location of malaria risk areas, but could not reliably recount their extent. This indicates a general, and perhaps intuitive, awareness among respondents, but little true, informed awareness.

Interestingly, despite the majority of respondents indicating that they were aware of malaria risk zones, only six felt that there was enough information available to the general public regarding malaria distribution, precautions to take against contracting malaria, and how to identify and treat malaria. Respondents who indicated that they were either aware of malaria risk areas prior to taking the questionnaire, or who indicated that they had some degree of awareness, were then asked to stipulate where they accessed this information. Importantly, government or official publications/websites were the least consulted $(n=2)$ source of information, while family, friends, or colleagues were the most frequently cited ( $n=15$ ) sources (Fig. 3). Many of the 11 respondents who selected "Other" indicated that they had accessed their information at school, through the media/news, or had been advised by a medical professional (Fig. 3). This could explain the lack of convergence between the government malaria map and those drawn by respondents.

Respondents were asked to rate the level of risk posed by malaria to South African citizens on a Likert scale of 1 to 5, with 1 being low risk, 3 being moderate risk, and 5 being high risk. Respondents most commonly $(n=11)$ rated the level of risk as moderate (as can be seen by the single peak), with a slight bias towards higher risk (Fig. 4).

\section{B - Avoidance of mosquito Bites}

Approximately three quarters $(n=23)$ of respondents indicated that they had taken precautions against contracting malaria during their most recent trip to a malaria risk area in Southern Africa, while eight reported taking no precautions and one declined to answer the question. Among the eight respondents who did not take precautions, the most commonly reported reasons were issues around risk assessment and lack of awareness. Interestingly, two respondents indicated that their risk assessment was informed by the advice of locals, with respondent 18 stating:

I heard from people who live there that it was not a risk.

Similarly, respondent 30 reported:

Been travelling to Mozam[bique] for a few years and nothing happened. Locals there also say they moved there and lived there for years - nothing happened.

A further two respondents stated that they were not aware that their destination was a malaria area before departing, and only 
Fig. 3 Sources used by respondents to access information regarding malaria distribution in Southern Africa (Respondents were able to select more than one option)

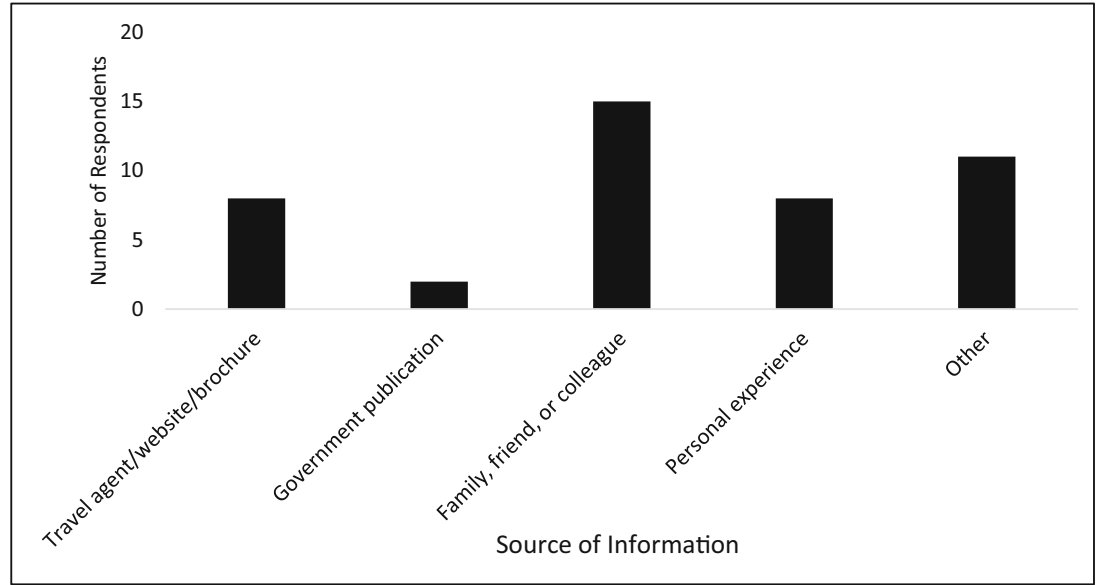

found out once they returned. For one of these respondents, their destination was Mozambique, a country classified as high risk in its totality. Of the eight respondents who did not take precautions, only one quarter $(n=2)$ indicated that they would change their behaviour and employ preventative measures on future trips.

For the 23 respondents who did take precautions, insect repellent was the most popular $(n=18)$ preventative measure used (Fig. 5). Insect repellent, along with travelling outside of the rainy season, were the two most common precautions used in isolation, each with four respondents. Only 12 respondents used more than one method simultaneously. Both respondents who selected the "Other" option (Fig. 5) cited wearing long trousers and long-sleeved shirts in the evenings. While this would minimize the chances of mosquito bites to the arms and legs, and is effective in reducing the irritation of mosquito bites, the efficacy of clothing worn in the evenings as a method of significantly reducing the risk of contracting malaria remains uncertain (Nakazawa et al. 1998; Del Prete et al. 2019). Long clothing worn throughout the day and night (Baker, 2018), and impregnated with insecticides (Shellvarajah et al. 2017), shows more promise, but this is not the approach indicated by the respondents. In this context, wearing long clothing only in the evenings is less effective than these alternatives, and their combined use with chemoprophylaxis (Baker, 2018).

Of the 23 respondents who did take precautions against contracting malaria, five indicated that they would only do so again on their next trip to a malaria area if it was in the rainy season/summer. One respondent (respondent 11) stated that they would not take any precautions, as they believed that:

risk is not significantly high when travelling for short time periods

This is a misconception, and studies of imported cases of malaria in Europe and the Middle East resulting from tourists' short trips to southern Africa underscore this (see Ben-Ami et al. 2005; Baranova et al. 2019). These erroneous sentiments are particularly concerning given the large proportion of respondents who obtain information on malaria risk from family, friends, and colleagues instead of government publications (Fig. 3).

\section{C - Compliance with Chemoprophylaxis, when indicated}

Chemoprophylaxis is indicated for travel to all malaria areas considered moderate to high risk (Schmidt, 2019a, b). These
Fig. 4 Level of risk posed by malaria to South African citizens according to respondents $(n=32)$

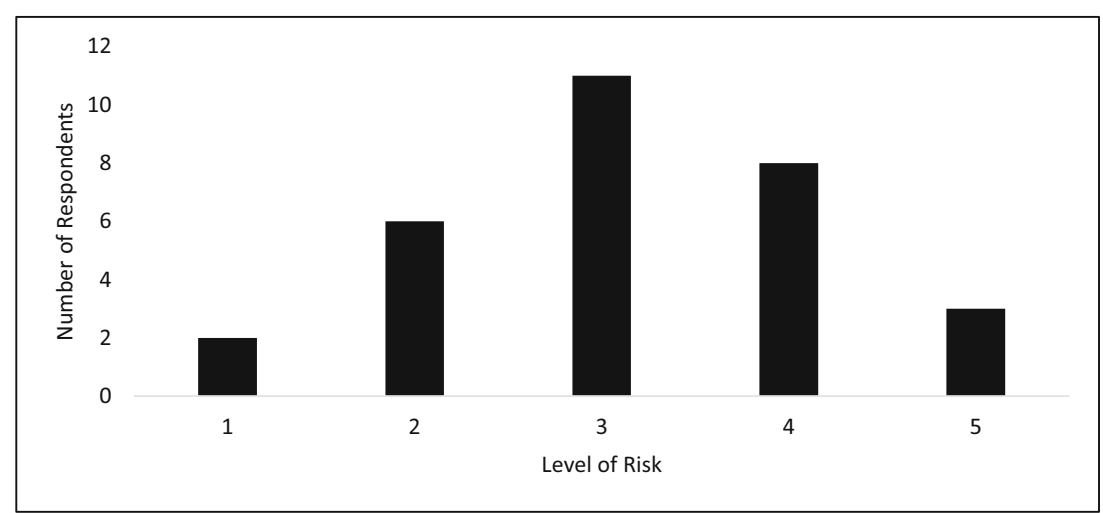


Fig. 5 Malaria prevention strategies employed by respondents (respondents were able to select more than one option)

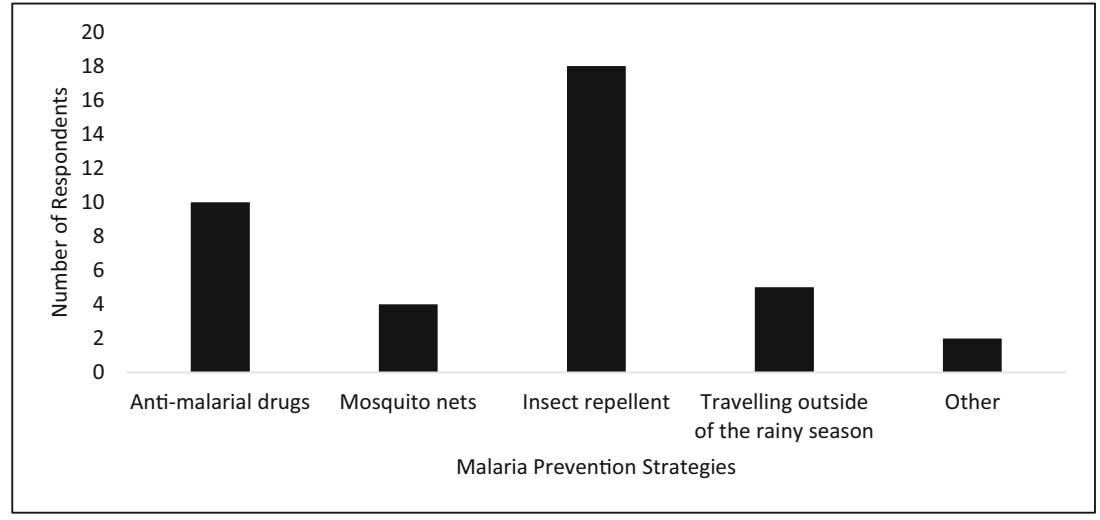

areas can be found in all of South Africa's neighbouring countries, and within South Africa in Limpopo and Mpumalanga (Fig. 1). Of the 32 respondents who submitted usable questionnaires, almost all $(n=30)$ indicated that they had travelled to malaria areas considered moderate or high risk. However, only one-third $(n=10)$ of these respondents reported that they had taken antimalarial drugs on their most recent trip to one of the areas. Even more alarmingly, of the 10 respondents who had only travelled locally within South Africa, to either Limpopo or Mpumalanga, only one-fifth $(n=2)$ had taken chemoprophylaxis. This indicates a very low level of compliance with chemoprophylaxis in indicated settings, which is particularly concerning among a sample group who have the level of education and socio-economic status to enable compliance.

\section{Climate change awareness and impact on future malaria risk zones}

All 32 respondents indicated they understood what was meant by the term "climate change". Respondents were then asked whether they thought climate change would impact malaria risk and distribution in Southern Africa, and if so, how. Almost all respondents $(n=28)$ indicated that they believed that climate change would increase malaria risk in Southern Africa, while the remaining four indicated that they did not know. No respondents answered that climate change would decrease malaria risk in Southern Africa or have no effect.

Respondents also drew a line across indicating where they thought the boundary of the malaria risk zone would be located in 20 years' time. The composite map produced shows a far greater extent of malaria distribution than the composite map produced for current malaria risk (Fig. 6). Respondents indicated that they believed the malaria risk zone would extend further west and south into the country's interior, with the majority of respondents including large parts of Limpopo and Mpumalanga (Fig. 6). This is consistent with the trend shown by the malaria risk maps produced by the government over the past century (Coetzee et al. 2013; Morris et al. 2013).
The composite map indicates that respondents are cognizant of the increased risk of malaria projected for South Africa in future decades, and significantly aware of the spatial patterns projected for the increase in the distribution of malaria risk. However, many respondents indicated an expansion of the malaria risk zone 20 years from now which is geographically impossible, and exceeds the model outputs for malaria projection. Notably, the expansion into the mountainous highlands of Lesotho, the temperate climates of the southern coast of South Africa, and the arid west coast of South Africa are unlikely in the next 20 years, if ever. These exaggerated perceptions of future risk, when not realized, may result in further complacency among respondents, particularly as relates to chemoprophylaxis.

\section{Discussion}

\section{Efficacy of the "ABC" of malaria prevention in increasing public awareness}

The first tenet of the "ABC" of malaria prevention relates to public awareness and the accurate assessment of malaria risk (NDOH 2018a). This emphasis on awareness and perception is further echoed in the Malaria Elimination Strategic Plan for South Africa 2019-2023 which aims to "ensure that $90 \%$ of the population affected by malaria receives information education communication messaging by 2023" (National Department of Health 2019:25). When respondents were surveyed, it was found that while there is a relatively high level of self-reported awareness regarding the general location of malaria risk areas in South Africa, the majority of respondents were unable to reliably recount the extent of these areas. The behaviour of the population regarding malaria avoidance similarly was not in line with governmental advice and scientifically determined best practice. This indicates that at least a proportion of the South African population are unaware of the precise location of the malaria risk zone, and their perceived awareness is incongruous with the demonstrated 
Fig. 6 Overlaid map of respondents' perceptions of future malaria risk boundaries in South Africa in 20 years' time $(n=28)$

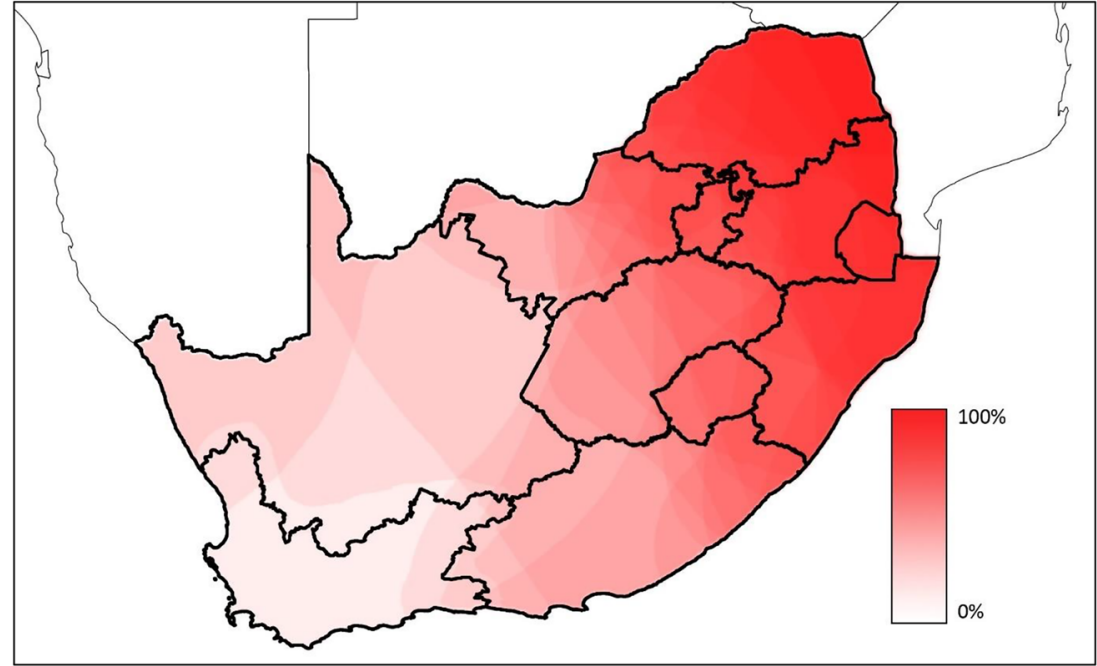

awareness or reality. This is consistent with prior research in KwaZulu-Natal (Maartens et al. 2007). Further research is needed to determine whether this lack of awareness in a statistically representative population amounts to greater than $10 \%$.

Within the existing medium to high-risk malaria zones (Fig. 1), targeted governmental efforts at increasing awareness have been conducted actively at the community level, rather than solely passively through websites and risk maps in clinics which is the case for the respondent group from Gauteng Province (Govere et al. 2000; Cox et al. 2018). For example, members of communities in the Vhembe District in largely rural Limpopo Province who have been involved in the governmental Malaria Awareness Programme (MAP) are found to have a 3.3 times greater knowledge on malaria transmission risk and 2.8 times higher awareness of prevention methods than those who had not been involved in these programmes (Cox et al. 2018). The perceptions of residents living in current malaria risk zones regarding the boundary of these zones would be a valuable avenue of future research.

It is notable that among the respondents, government and official publications/websites were the least consulted sources of information, while family, friends, and/or colleagues were the most frequently consulted. As only six of the 32 respondents believed that there was enough information available to the general public regarding malaria distribution, precautions to take against contracting malaria, and how to identify and treat malaria, this suggests a weakness in policy's strategies regarding modes of delivery of malaria education and highlights the possibility of the transmission of misinformation from person to person. While targeted initiatives in high-risk malaria regions are of course imperative in addressing the epicentre of the problem, the significant tourism sector in South Africa, and the large proportion of people migrating back to their homes in malaria areas during holiday periods, does necessitate a broader geographic reach of these activities
(Blumberg et al. 2014; Raman et al. 2016). Following discrete epidemics, this has been facilitated through tourism operators distributing information (Maartens et al. 2007), but this would not address tourists staying in less formalized accommodation. The incorrect perceptions that malaria risk is not high when travelling for short periods (see Ben-Ami et al. 2005; Baranova et al. 2019), or can be mitigated through wearing long clothing only in the evenings, reveal the dangers of relying on non-official sources of information when planning precautionary measures to avoid malaria (Raman et al. 2016). These respondents appear to have misunderstood that while the longer the visit to a malaria-prone region, the greater the risk, short stays do not carry no or low risk; likewise, while long clothing is advised at all times, wearing it for short periods is not sufficient in preventing the risk of bites or malaria (Baker 2018). This misconception appears relatively unique to this study; an investigation into foreign tourists' awareness of malaria while at OR Tambo International Airport in Gauteng indicated that medical practitioners and travel agents were by far the greatest source of information on malaria (Waner et al. 1999).

The low rates of use of chemoprophylaxis among respondents warrant particular concern. For persons with no immunity to malaria, which includes our study sample group, but also much of South Africa (Fig. 1), chemoprophylaxis is indicated for the period of travel (Freedman 2008; Morris et al. 2013; Schmidt, 2019a, b). Doxycycline, atovaquone-proguanil, and mefloquine are currently recommended for use in South Africa, with an efficacy of $\sim 90 \%$ when taken correctly (Baker, 2018; Schmidt, 2019a, b). The former two drugs have recently been downscheduled to S2, allowing for pharmacists to dispense these without prescription (Baker 2018), thus increasing access and reducing costs slightly through eliminating the necessity for a consultation with a doctor (Ukpe et al. 2013). While there are medical uncertainties regarding the safety of certain antimalarials, particularly Mefloquine, in terms of neuropsychiatric adverse effects 
(Freedman 2008; Baker 2018), these were not cited by the respondents as the reasons for non-compliance. More minor side effects, by contrast, were indicated as a reason for non-compliance, a theme which is echoed in studies of international tourists (Waner et al. 1999). A lack of awareness of the need for chemoprophylaxis, due to poor knowledge of the malaria areas, or to a lack of understanding of the severity of the risk may explain some of respondents not having used this precaution (Leggat et al. 2002; Maartens et al. 2007). However, as the majority of respondents over-estimated the expanse of the South African malaria risk area, this seems unlikely. A significant barrier to the use of chemoprophylaxis is the cost (Leggat et al. 2002; Ukpe et al. 2013). Even among more affluent travellers, the large cost of the antimalarial drugs serves as disincentive, particularly for trips of short duration or outside of the rainfall season (Leggat et al. 2002). Greater medical aid coverage for antimalarials and a reduction in the cost of the drugs would be important in addressing this component.

\section{The way forward: policy directions}

Despite a relatively low sample size, this study reveals notable gaps in the awareness and risk-taking decision-making among persons who travel into malaria areas, who are resident in a country in which some but not all areas carry a high malaria risk (Blumberg et al. 2014). This is distinct to the majority of studies for South Africa which either assess the awareness and behaviour of international tourists visiting malaria areas (cf. Waner et al. 1999; Freedman 2008), or of local communities within high-risk malaria areas (cf. Govere et al. 2000; Morris et al. 2013; Cox et al. 2018). This group is important because they do not receive the same level of travel advice as international tourists (Waner et al. 1999), yet frequently travel into and through high- and medium-risk malaria areas (Maartens et al. 2007), often through self-booking (de Jager and Ezeuduji 2015). The greatest awareness among local tourists has been found to directly follow major malaria epidemics, which is coupled with booking cancellations for accommodation establishments in malaria-prone regions (Maartens et al. 2007). The changes in the methods of malaria risk mapping, and the extent of the risk areas in these maps, particularly under climate change, further yield much of the information that regular travellers might have outdated (Coetzee et al. 2013; Morris et al. 2013). Policy improvements therefore need to be aware of both the limitations in knowledge and shortfalls in risk-aversion behaviour, and the potential for these factors to worsen under climate change. For effective policy adaptation, however, a much larger sample group with greater socioeconomic heterogeneity would be valuable.

While the regularly shifting extent of the malaria risk zone is posited as one of the reasons for a poor awareness among respondents, it could be argued that under climate change, an even more frequent updating and reporting of risk may be beneficial. Seasonal malaria forecasts are being produced for
South Africa by local researchers (Kim et al. 2019; Landman et al. 2020), which could be presented to the public biannually to refine malaria prevention behaviour. Frequent and standardized government publication of season-specific information would potentially result in a greater reliance on these resources over word-of-mouth based on travel which occurred less recently. The avenues of the dissemination are also an important consideration in effective communication of malaria information (Blumberg et al. 2014).

Finally, this study was conducted during 2019, prior to the COVID-19 pandemic (Gilbert et al. 2020). This pandemic has, both globally and in South Africa, revealed an unprecedented public engagement with disease epidemiology and risk-aversion, and the extensive use of social media in government communication (Gao et al. 2020). South Africa has been ranked second in the world for the most reliable COVID19 information, due in part to the conditions of the national lockdown which prohibit the dissemination of fake news (Ryklief 2020). Announcements directly from the National Institute for Communicable Diseases and the Minister of Health, each of which distributed both to the press and via social media, have allowed the public to follow both case numbers and the state of knowledge on precautionary measures. This provides valuable insight into methods of effective communication with the national populace involving disease prevention (Young et al. 2008).

\section{Conclusion}

This pilot study explores the self-reported risk behaviour and awareness of malaria area boundaries among South Africans who are resident outside of the high-risk malaria area. While respondents in this study claim to have a high level of awareness relating to malaria, the vast majority overestimate the spatial extent of both the current and future malaria areas and do not practice the indicated precautionary measures when visiting regions that they report to understand to be malaria-prone. Part of this disjunct between their understanding of the malaria areas and their behaviour appears to relate to their sources of information, with a considerable reliance on friends and family, rather than official sources. While this pilot study involves a small target group who cannot be considered representative of any broader sub-population, we provide insight as to avenues for more comprehensive research, and a methodology which could be used. This more extensive research would provide valuable insight to improve policy and intervention.

\section{Compliance with ethical standards}

Ethics clearance was obtained from the University of the Witwatersrand's Human Research Ethics Committee (non-medical) prior to entering the field (ethics clearance: gaes-2019-06-01). 


\section{References}

Abiodun GJ, Adebiyi B, Abiodun RO, Oladimeji O, Oladimeji K, Adeola AM et al (2020) Investigating the resurgence of malaria prevalence in South Africa between 2015 and 2018: a scoping review. Open Health J 13(1):199-125

Adeola A, Ncongwane K, Abiodun G, Makgoale T, Rautenbach H, Botai J, Adisa O, Botai C (2019) Rainfall trends and malaria occurrences in Limpopo Province, South Africa. Int J Env Res Pub He 16(24): 5156

Alonso P, Noor AM (2017) The global fight against malaria is at crossroads. Lancet 390(10112):2532-2534

Baker L (2018) Malaria prophylaxis - can we conquer the 'mighty' parasite? SA Pharm J 85(2):48-54

Baranova A, Sergiev V, Morozova L, Turbabina N, Morozov E (2019) Imported plasmodium vivax malaria in the Russian federation from Western Sub-Saharan Africa. J Trop Med 2019:1-5. https://doi.org/ 10.1155/2019/4610498

Ben-Ami R, Siegman-Igra Y, Anis E, Brook GJ, Pitlik S, Dan M, Giladi $M$ (2005) Malaria in travelers returning from short organized tours to holiday resorts in Mombassa, Kenya. Isr Med Assoc J 7:364-367

Bernard H (2013) Social research methods: qualitative and quantitative approaches, 2nd edn. SAGE, Los Angeles

Bird D (2009) The use of questionnaires for acquiring information on public perception of natural hazards and risk mitigation - a review of current knowledge and practice. Nat Hazard Earth Sys 9(4):13071325

Blumberg L, Frean J, Moonasar D (2014) Successfully controlling malaria in South Africa. SAMJ 104(3):224-227

Caminade C, Kovats S, Rocklov J, Tompkins A, Morse A, ColónGonzález F et al (2014) Impact of climate change on global malaria distribution. PNAS 111(9):3286-3291

Cella W, Baia-da-Silva DC, Melo GCD, Tadei WP, Sampaio VDS, Pimenta P, Lacerda MVG, Monteiro WM (2019) Do climate changes alter the distribution and transmission of malaria? Evidence assessment and recommendations for future studies. Revista da Sociedade Brasileira de Medicina Tropical 52

Coetzee M, Kruger P, Hunt R, Durrheim D, Urbach J, Hansford C (2013) Malaria in South Africa: 110 years of learning to control the disease. SAMJ 103(10):770-778

Cohuet A, Harris C, Robert V, Fontenille D (2010) Evolutionary forces on Anopheles: what makes a malaria vector? Trends Parasitol 26(3): 130-136

Cox SN, Guidera KE, Simon MJ, Nonyane BAS, Brieger W, Bornman MS, Kruger PS (2018) Interactive malaria education intervention and its effect on community participant knowledge: the malaria awareness program in Vhembe district, Limpopo, South Africa. Int Quart Comm Health Edu 38(2):147-158

De Jager K, Ezeuduji IO (2015) Socio-demographic variables' relationships in choosing between travel agencies and the internet for leisure travel arrangements: the case of South Africa. Afr J Hosp Tour Leisure 4(2):1-14

Del Prete V, Mateo-Urdiales A, Bueno-Cavanillas A, Ferrara P (2019) Malaria prevention in the older traveller: a systematic review. J Travel Med 26(7). https://doi.org/10.1093/jtm/taz067

Eikenberry SE, Gumel AB (2019) Mathematics of malaria and climate change. In: Kaper HG, Roberts FS (eds) Mathematics of planet earth. Springer, Cham, pp 77-108

Erhardt L, Hobbs FD (2002) Public perceptions of cardiovascular risk in five European countries: the react survey. Int J Clin Pract 56(9):638 644

Freedman DO (2008) Malaria prevention in short-term travellers. New Engl J Med 359(6):603-612

Gao J, Zheng P, Jia Y, Chen H, Mao Y, Chen S, Wang Y, Fu H, Dai J (2020) Mental health problems and social media exposure during
COVID-19 outbreak. PlosOne 15(4):e0231924. https://doi.org/10. 1371/journal.pone.0231924

Gilbert M, Pullano G, Pinotti F, Valdano E, Poletto C, Boëlle PY, D’Ortenzio E, Yazdanpanah Y, Eholie SP, Altmann M, Gutierrez B, Kraemer MUG, Colizza V (2020) Preparedness and vulnerability of African countries against importations of COVID-19: a modelling study. Lancet 395(10227):871-877

Glik D, Harrison K, Davoudi M, Riopelle D (2004) Public perceptions and risk communications for botulism. Biosecur 2(3):216-223

Goldman RE, Parker DR, Eaton CB, Borkan JM, Gramling R, Cover RT, Ahern DK (2006) Patients' perceptions of cholesterol, cardiovascular disease risk, and risk communication strategies. Ann Fam Med 4(3):205-212

Govere J, Durrheim D, la Grange K, Mabuza A, Booman M (2000) Community knowledge and perceptions about malaria and practices influencing malaria control in Mpumalanga Province, South Africa. SAMJ 90(6):611-618

Kim Y, Ratnam JV, Doi T, Morioka Y, Behera S, Tsuzuki A et al (2019) Malaria predictions based on seasonal climate forecasts in South Africa: a time series distributed lag nonlinear model. Nat Sci Rep 9(1):1-10

Landman WA, Sweijd N, Masedi N, Minakawa N (2020) The development and prudent application of climate-based forecasts of seasonal malaria in the Limpopo province in South Africa. Env Dev 35: 100522. https://doi.org/10.1016/j.envdev.2020.100522

Leggat PA, Dürrheim DN, Blumberg L (2002) Trends in malaria chemoprophylaxis prescription in South Africa 1994 to 2000. J Trav Med 9(6):318-321

Maartens F, Sharp B, Curtis B, Mthembu J, Hatting I (2007) The impact of malaria control on perceptions of tourists and tourism operators concerning malaria prevalence in KwaZulu-Natal, 1999/2000 versus 2002/2003. J Trav Med 14(2):96-104

Maharaj R, Seocharan I, Qwabe B, Mkhabela M, Kissoon S, Lakan V (2019) Decadal epidemiology of malaria in KwaZulu-Natal, a province in South Africa targeting elimination. Malar J 18(1):368

Makinde OS, Abiodun GJ (2019) The impact of rainfall and temperature on malaria dynamics in the KwaZulu-Natal province. South Africa Comm Stat 6:97-108. https://doi.org/10.1080/23737484.2019. 1699000

Morris N, Frean J, Baker L, Ukpe I, Barnes K, Kruger P et al (2013) Redefining the extent of malaria transmission in South Africa: implications for chemoprophylaxis. SAMJ 103(11):861-864

Nakazawa M, Ohmae H, Ishii A, Leafasia J (1998) Malaria infection and human behavioral factors: a stochastic model analysis for direct observation data in the Solomon Islands. Am J Hum Biol 10(6): 781-789

NDoH (2018a) National guidelines for the prevention of malaria, South Africa 2018. National Department of Health, Pretoria

NDoH (2018b) South African malaria risk map (December 2018. http:// wwwnicdacza/wp-content/uploads/2018/12/south africa malaria risk_dec2018_finalpdf

National Department of Health (2019) Malaria elimination strategy plan for South Africa 2019-2023, Pretoria

Raman J, Morris N, Frean J, Brooke B, Blumberg L, Kruger P, Mabusa A, Raswiswi E, Shandukani B, Misani E, Groepe MA, Moonasar D (2016) Reviewing South Africa's malaria elimination strategy (2012-2018): progress, challenges and priorities. Malar J 15(1):438

Roffe SJ, Fitchett JM, Curtis CJ (2019) Classifying and mapping rainfall seasonality in South Africa: a review. S Afr Geogr J 101(2):158-174

Ryklief S (2020) South Africa ranks second in the world for reliable Covid-19 news. Independent Online. https://www.iol.co.za/news/ south-africa/south-africa-ranks-second-in-the-world-for-reliablecovid-19-news-46850429.

Schmidt S (2019a) Malaria: the "unwanted souvenir". S Afr Pharm Assist 19(4):8-13 
Seale H, Heywood AE, McLaws ML, Ward KF, Lowbridge CP, Van D et al (2010) Why do I need it? I am not at risk! Public perceptions towards the pandemic (H1N1) 2009 vaccine. BMC Infect Dis 10(1): 99

Shellvarajah M, Hatz C, Schlagenhauf P (2017) Malaria prevention recommendations for risk groups visiting sub-Saharan Africa: a survey of European expert opinion and international recommendations. Trav Med Infect Dis 19:49-55

Schmidt S (2019b) Malaria: the unwanted souvenir. SA Pharm Assist 19(4):8-13

Ukpe IS, Moonasar D, Raman J, Barnes KI, Baker L, Blumberg L (2013) Case management of malaria: treatment and chemoprophylaxis. SAMJ 103(10):793-798

Waner S, Durrhiem D, Braack LEO, Gammon S (1999) Malaria protection measures used by in-flight travelers to South African game parks. J Trav Med 6(4):254-257
WHO (2018) Update on the E-2020 initiative of 21 malaria-eliminating countries: report and country briefs. World Health Organization, Geneva

WHO (2019a) Fact sheet about malaria. https://wwwwhoint/en/newsroom/fact-sheets/detail/malaria Accessed 13 March 2019

WHO (2019b) World malaria report. World Health Organization, Geneva Young ME, Norman GR, Humphreys KR (2008) Medicine in the popular press: the influence of the media on perceptions of disease. PLoSOne 3(10):e3552. https://doi.org/10.1371/journal.pone. 0003552

Publisher's note Springer Nature remains neutral with regard to jurisdictional claims in published maps and institutional affiliations. 